\title{
A NEW AGOROPHIID FROM SAN JUAN DE LA COSTA, BAJA CALIFORNIA SUR; THE OLDEST FOSSIL ODONTOCETE FROM MEXICO
}

CRUZ-MARIN* ${ }^{*}$, Arturo, Centro Interdisciplinario de Ciencias Marinas, I.P.N. Apartado Postal 592, La Paz, Baja California Sur, C.P. 23000, México; BARNES, Lawrence G., Natural History Museum of Los Angeles County, 900 Exposition Boulevard, Los Angeles, California 90007, U.S.A.

An important new fossil odontocete in the primitive, extinct cetacean family Agorophiidae has been discovered in the El Cien Formation exposed along the western shore of Bahia de La Paz, Baja California Sur. This formation is a regressive sequence of marine sediment and includes a fossiliferous layer called Capa Humboldt Superior (phosphoarenite) in its medial part. Geological studies show that the site was an area of shallow water during Late Oligocene time. Agorophiidae are chronologically and morphologically intermediate between the primitive Archaeoceti and more typical Odontoceti. A poor fossil record exists for the Agorophiidae. The new specimen includes the skull, mandible, anterior vertebrae, ribs and forelimb, and represents a previously undescribed genus and species. It has elongated and single-rooted anterior teeth, two-rooted posterior teeth with serrated crowns, a long snout, flexible and unfused cervical vertebrae, a relatively large pectoral flipper, and was approximately $2 \mathrm{~m}$ in body length. It lacked cranial asymmetry, and this suggests that it did not have sophisticated echolocation abilities. More highly evolved than Agorophius from the North Atlantic (the type gens of the family), the new cetacean from Mexico shares some important characters with the more dolphin-like Squalodontidae. It is the first record of an agorophiid from the eastern North Pacific, the oldest fossil odontocete reported from Mexico, and demonstrates some of the evolutionary steps between Archaeoceti and later Odontoceti. 